\title{
DINÂMICA ESPAÇO-TEMPORAL DAS ÁREAS VERDES URBANAS NA CIDADE DE CASTELO, ESTADO DO ESPÍRITO SANTO, BRASIL
}

\author{
SPATIAL-TEMPORAL DYNAMICS OF URBAN GREEN AREAS IN THE CITY OF \\ CASTELO, ESPIRITO SANTO STATE, BRAZIL
}

Caio Henrique Ungarato Fiorese ${ }^{1}$, Vinicius Rocha Leite ${ }^{2}$, Gilson Silva Filho ${ }^{3}$, Tatiana da Silva Lopes ${ }^{4}$

\begin{abstract}
RESUMO
O objetivo desta pesquisa foi mapear as áreas verdes urbanas do município de Castelo-ES e propor sugestões para melhorias na arborização local. Um Sistema de Informação Geográfica foi usado para analisar imagens aéreas de alta resolução espacial em conjunto a informações cartográficas. Procedimentos de fotointerpretação das áreas verdes foram realizados na escala de 1:1000. A distribuição da arborização urbana foi espacializada conforme a localização por bairros, sendo quantificada por meio do Índice de Áreas Verdes (IAVT) e Índice de Áreas Verdes Recreativas (IAVR). Ao longo do período estudado, a arborização decresceu $67 \%$ nos bairros da cidade. Embora os Índices de Áreas Verdes quantificados sejam considerados satisfatórios, estando acima do mínimo exigido pela Organização Mundial da Saúde (OMS) e Sociedade Brasileira de Arborização Urbana (SBAU), eles decresceram no período de análise. O IAVR estimado não foi satisfatório, sendo um problema para o planejamento urbano. As áreas verdes estão concentradas principalmente em locais não efetivamente urbanizados. A execução de melhorias na arborização das vias públicas e a criação de novos parques/praças são medidas necessárias para aumentar a qualidade de vida e do ambiente.
\end{abstract}

Palavras-chave: Geoprocessamento; Qualidade ambiental; Arborização urbana.

\begin{abstract}
The objective of this research was to map the urban green areas of the municipality of Castelo-ES and propose suggestions for improvements in local afforestation. A Geographic Information System was used to analyze high spatial resolution aerial photographs along with cartographic information. Procedures for photointerpretation of the green areas were performed on a scale of 1: 1000. The urban afforestation distribution was spatialized according to the location by neighborhoods, being quantified through the Index of Green Areas (IAVT) and Index of Recreational Green Areas (IAVR). During the studied period, tree planting declined $67 \%$ in the city's neighborhoods. Although the quantified Green Area Indices are considered satisfactory, being above the minimum required by the World Health Organization (WHO) and the Brazilian Society of Urban Afforestation (SBAU), they decreased during the analyzed period. The estimated IAVR was not satisfactory, being a problem in urban planning. The green areas are concentrated mainly in places not effectively urbanized. The execution of improvements in the afforestation of public roads and the creation of new parks/plazas are necessary measures to increase the quality of life and the environmental quality.
\end{abstract}

Keywords: Geoprocessing; Environmental quality; Urban afforestation.

Recebido em 20.08.2020 e aceito em 15.04.2021

1 Engenheiro Ambiental. Mestrando em Agroquímica. Aluno de Pós-Graduação da Universidade Federal do Espírito Santo. Alegre/ES. Email: caiofiorese@hotmail.com

2 Biólogo. Doutor em Ecologia e Recursos Naturais. Pesquisador do Instituto Gota Verde. Cachoeiro de Itapemirim/ES. Email: viniciusrleite@gmail.com

3 Engenheiro Agrônomo. Doutor em Ecologia e Recursos Naturais. Professor Titular do Centro Universitário São Camilo. Cachoeiro de Itapemirim/ES. Email: silva.gilson.filho@gmail.com

4 Bióloga. Doutora em Genética e Melhoramento de Plantas. Professora do Centro Universitário São Camilo. Cachoeiro de Itapemirim/ES. Email: tslopes11@gmail.com 


\section{INTRODUÇÃO}

A humanidade vem se transferindo paulatinamente do meio rural para os centros urbanos, em um padrão atribuído à busca pela facilidade de acesso a comunicação, a serviços de saúde e de educação. Dessa forma, com o aumento da população nas cidades, a harmonização entre o crescimento econômico e o equilíbrio ambiental passou também a ser uma temática de grande importância na evolução do bem-estar da sociedade, já que o meio ambiente é um dos ícones do desenvolvimento sustentável e está ligado aos anseios humanos (FURLANETO; SILVA; CORREA, 2014).

A necessidade da manutenção da vegetação em zonas urbanas é justificável pelo seu potencial em gerar diretamente um aumento de qualidade de vida às populações. A cobertura vegetal afeta diretamente o conforto humano nas cidades, amenizando os impactos negativos de um processo de urbanização acelerado sem um correto planejamento e ordenamento territorial. Isso faz com que problemas como o aumento da poluição atmosférica e desestabilização hídrica sejam continuamente gerados, em consonância com as alterações nos microclimas locais e geração de inundações (BARGOS; MATIAS, 2012).

Maciel e Barbosa (2015) conceituam áreas verdes urbanas como sendo locais de vegetação arbórea, presentes em ambientes urbanos de convivência social, como é o caso das praças, parques, terrenos baldios e cemitérios, possuindo também função de ornamentar alguns desses lugares com aumento da harmonização ambiental pela melhoria na qualidade paisagística. Essas áreas verdes, incluindo os parques e as praças são percebidos como importantes espaços de convivência e interação social, além de estreitar a relação humana com a natureza. Com a presença dessas áreas, aspectos positivos podem ser viabilizados aos frequentadores desses locais, como, por exemplo, a prática de atividades físicas e lazer (DORIGO; LAMANO-FERREIRA, 2015).

$\mathrm{Na}$ questão ambiental, as áreas verdes atuam prestando serviços ecossistêmicos, como estabilização de superfícies através da fixação do solo pelas raízes das plantas que estabelecem obstáculos contra ventos, protegem a qualidade da água e impedem o escoamento de materiais poluidores para os cursos hídricos. Além disso, elas filtram o ar, equilibram os índices de umidade relativa do ar, abrigam a fauna e atenuam o impacto pluvial, minimizando as consequências do escoamento superficial da água das chuvas (SILVA; PEREIRA; WICKERT, 2018).

Todavia, os espaços verdes estão vulneráveis ao gerenciamento de forma irregular, proporcionando aspectos negativos, dentre os quais Dorigo e Lamano-Ferreira (2015) destacam a falta de segurança, limpeza e conservação dos equipamentos e estrutura em geral. Alberto (2017) afirma que muitos desses espaços verdes, quando existentes, não correspondem a todas as aspirações do bem-estar humano, ou são insuficientes devido à altíssima demanda da 
crescente população em áreas urbanizadas. Diante desse cenário, a existência da cobertura vegetal pode ser empregada como referência de análise e é, de fato, relevante na mensuração da qualidade ambiental urbana (PANCHER; ÁVILA, 2012).

Nas tomadas de decisões sobre a situação do ambiente urbano, as técnicas de Sensoriamento Remoto, por meio de imagens aerofotogramétricas de alta resolução espacial, tomadas em diferentes períodos do tempo, permitem realizar um levantamento dos dados da superfície terrestre e espacializar as alterações temporais ocorridas. Assim, com a utilização das técnicas de mapeamento da vegetação com uso de geoprocessamento e como um instrumento de construção de um panorama ambiental das áreas verdes, é facilitada a obtenção de diagnósticos e geração de prognósticos eficientes voltados à realidade do local estudado (SANTOS; NETTO; CASTRO, 2012). Nesse sentido, o objetivo da presente investigação foi avaliar e quantificar a presença e a distribuição espacial de diferentes classes de áreas verdes urbanas existentes no município de Castelo, no estado do Espírito Santo, bem como propor sugestões de melhorias locais a partir dos resultados obtidos.

\section{MATERIAL E MÉTODOS}

O limite urbano de Castelo-ES foi considerado como área de abrangência do presente estudo, e está localizado na macrorregião Sul do estado do Espírito Santo. A sede da cidade localiza-se entre as coordenadas geográficas (latitude $20^{\circ} 36^{\prime} 13^{\prime \prime}$ sul e a longitude $41^{\circ} 11^{\prime} 05^{\prime \prime}$ oeste), a uma altitude média de 100 metros do nível do mar.

Em sua zona rural, o município possui como base econômica a agropecuária, sendo a cafeicultura a atividade agrícola principal, mas também apresenta como destaque atividade ligada ao desenvolvimento do turismo, da agroindústria e do artesanato (INCAPER, 2010). A Figura 1 mostra a localização geográfica do município estudado e de sua área urbanizada que foi alvo da presente análise.

Os procedimentos desta pesquisa foram realizados no aplicativo computacional ArcGIS ${ }$, na versão 10.2.2. Inicialmente, junto ao banco de dados disponibilizado pelo Sistema Integrado de Bases Geoespaciais do estado do Espírito Santo (GEOBASES), fotografias aéreas do local de estudo foram adquiridas em formato ECW (Enhanced Compression Wavelet), sendo provenientes dos Ortofotomosaicos do Instituto Estadual de Meio Ambiente e Recursos Hídricos (IEMA) referentes aos mapeamentos realizados nos anos de 2008 e 2012-2015, com resolução espacial de 1 metro e 0,25 metro, respectivamente. 


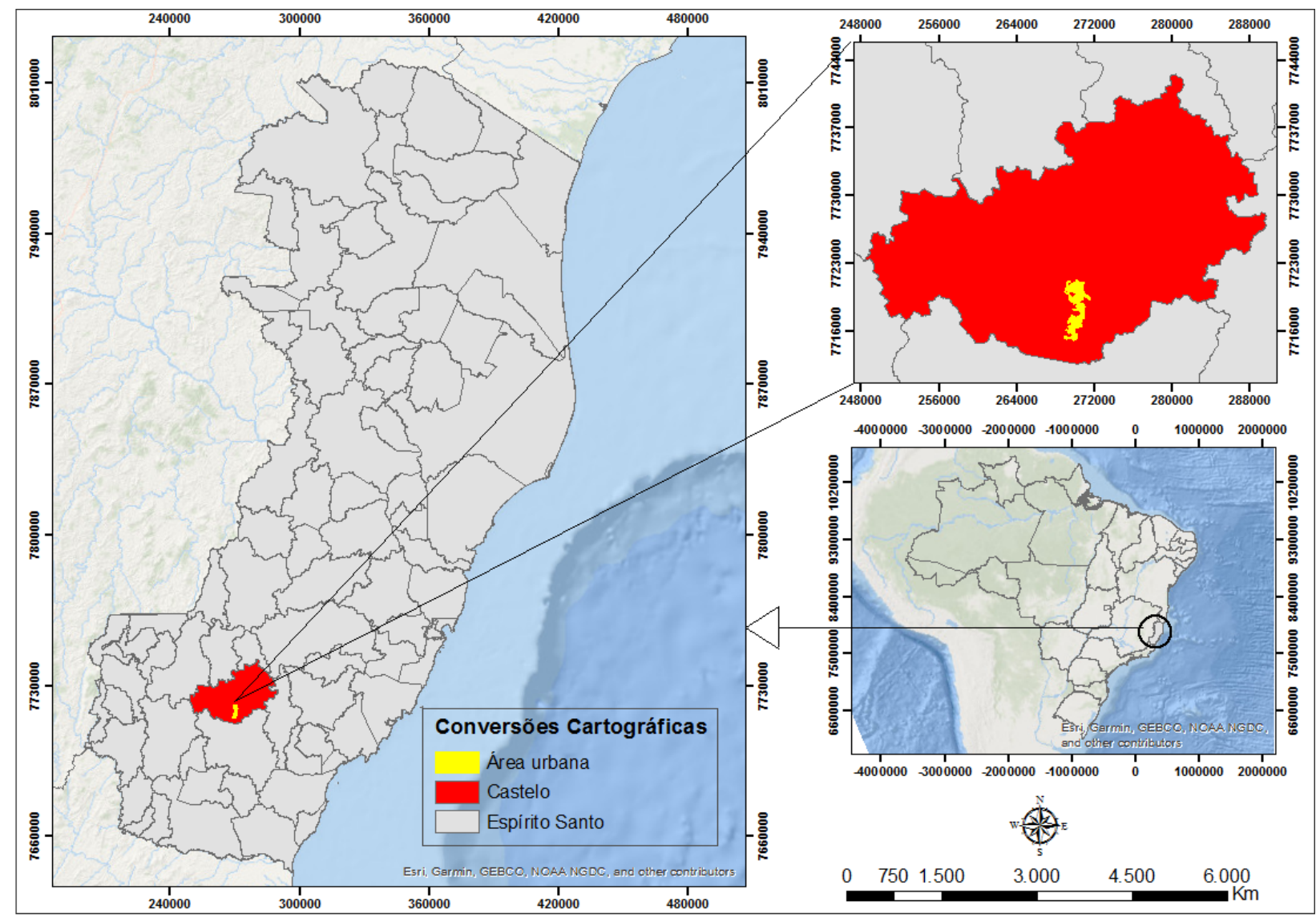

Figura 1. Localização geográfica da cidade de Castelo-ES e de sua zona urbanizada.

Figure 1. Geographic location of the city of Castelo-ES and its urbanized zone.

Em seguida, foram utilizadas as feições das zonas urbanas do estado do Espírito Santo disponibilizadas pelo Instituto Jones dos Santos Neves (IJSN). Com o Sistema de Informação Geográfica instaurado, os procedimentos foram realizados separadamente para as imagens dos anos 2008 e 2013. Com auxílio de recursos de edição das fotografias em formato matricial, um recorte foi realizado para delimitar somente a área de interesse contendo apenas a zona urbana.

As atividades de mapeamento das áreas verdes urbanas foram realizadas através da fotointerpretação das feições na escala 1:1000, em ambos os mapeamentos. Para tal, informações acerca da classificação das áreas verdes adotadas por Santos e Magri (2018) e Pirovani et al. (2012) foram consideradas, conforme apresentado na Tabela 1. Já as feições de praças e parques urbanos, canteiros centrais e rotatórias, foram identificadas nas imagens por meio da criação de um arquivo em formato vetorial, para cada classe considerada.

Quanto às áreas de arborização, foram coletadas diferentes amostras, entre 150 a 170, com intuito de obter maior precisão nos resultados, considerando que ainda não há uma definição exata na literatura a respeito do número de amostras. Como exemplo, Fiorese e Silva Filho (2019), em trabalhos voltados ao mapeamento das áreas verdes urbanas do município de Guaçuí-ES, consideraram o número de 200 amostras para cada classe. Em contrapartida, 
Nascimento et al. (2016) consideraram 30 amostras para cada classe de uso e ocupação do solo no município de Cáceres-MT. Portanto, a adoção do número de amostras das áreas verdes de Castelo-ES não foi fundamentada em uma base específica, embora tenha sido considerado que quanto maior fosse o número de amostras para cada classe, maior seria a precisão dos resultados finais. E esse mapeamento da arborização foi possível através da ferramenta image classification no ArcGIS $®$, obtendo, assim, os locais onde há predominância desta classe. Após esses procedimentos, um layout final com o mapeamento das classes de áreas verdes foi obtido para a zona urbana do município de Castelo-ES.

Tabela 1. Classificação adotada para os locais contendo as áreas verdes urbanas.

Table 1. Classification adopted for the sites containing urban green areas.

\begin{tabular}{cc}
\hline Classe & Descrição \\
\hline Arborização & Locais com vegetação nativa ou arbórea, em áreas públicas e particulares. \\
$\begin{array}{c}\text { Praças e parques } \\
\text { urbanos }\end{array}$ & $\begin{array}{r}\text { Locais com função recreacional, podendo abrigar equipamentos como bancos, } \\
\text { mesas, materiais de academia, dentre outros. }\end{array}$ \\
$\begin{array}{c}\text { Canteiros centrais } \\
\text { e rotatórias }\end{array}$ & Locais sem caráter conservacionista nem recreacional, mas de função \\
ornamental.
\end{tabular}

Fonte: Santos e Magri (2018); Pirovani et al. (2012).

Em seguida, o Índice de Áreas Verdes (IAVT) foi estimado para a cidade. No cálculo do IAVT, Santos e Magri (2018) afirmam que a estimativa do índice considera o somatório das áreas livres (em metros quadrados), dividido pelo número de habitantes da zona urbana.

$$
\mathrm{IAVT}=\frac{\sum \mathrm{AT}}{\mathrm{N}}
$$

Em que:

IAVT = Índice de Áreas Verdes ( $\mathrm{m}^{2} /$ habitante);

$\mathrm{N}=$ Número de habitantes da zona urbana;

AT $=$ Áreas verdes urbanas $\left(\mathrm{m}^{2}\right)$.

O número de habitantes residentes na área urbana e considerado para todas as estimativas foi consultado conforme o censo demográfico realizado no ano de 2010 pelo Instituto Brasileiro de Geografia e Estatística (IBGE). Para o município estudado, o Índice de Áreas Verdes Recreativas (IAVR) também foi estimado, considerando apenas as áreas de praças e parques urbanos. Esse índice é expresso através da divisão do número de áreas verdes recreativas $\left(\mathrm{em}^{2}\right.$ ) pelo número de habitantes da zona urbana. 


$$
\operatorname{IAVR}=\frac{\sum \mathrm{AR}}{\mathrm{N}}
$$

Em que:

IAVR = Índice de áreas verdes recreativas ( $\mathrm{m}^{2} /$ habitante);

$\mathrm{N}=$ Número de habitantes da zona urbana;

$\mathrm{AR}=$ Áreas verdes urbanas recreativas $\left(\mathrm{m}^{2}\right)$.

Com intuito de estudar o mapeamento das áreas verdes urbanas por bairro da zona urbana de Castelo, um arquivo em formato vetorial, contendo os limites de bairros espacializados, foi consultado junto ao sítio eletrônico do IJSN. Com auxílio das ferramentas de recorte de arquivos, em formato rasterizado, foi possível mapear as classes de área verde para cada bairro e analisá-las posteriormente. Outras estimativas de IAVT e IAVR foram obtidas para cada bairro da cidade por consulta ao número de habitantes em dados por setores censitários disponibilizados pelo IBGE. A partir dos resultados de porcentagem de arborização, um mapa foi desenvolvido contendo as reduções e acréscimos na área arborizada por bairro por meio da subtração das porcentagens do ano de 2013 pelas mapeadas no ano de 2008.

Todos os resultados obtidos a partir dos índices foram comparados conforme outros trabalhos realizados com fundamentação metodológica semelhante e com os valores mínimos de áreas verdes por habitante estabelecidos pela Organização Mundial da Saúde (OMS) e Sociedade Brasileira de Arborização Urbana (SBAU), sendo considerada a quantidade mínima para assegurar qualidade de vida em uma cidade (PIROVANI et al., 2012). Os valores mínimos de $12 \mathrm{~m}^{2} /$ hab. sugerido pela SBAU e de $15 \mathrm{~m}^{2} /$ hab. recomendado pela OMS foram utilizados em outros trabalhos, como por exemplo o de Bargos e Matias (2012).

\section{RESULTADOS E DISCUSSÃO}

As áreas verdes mapeadas, com base nas imagens dos anos de 2008, podem ser observadas em meio às estruturas relacionadas da malha urbana (Figura 2). No caso da arborização na cidade de Castelo-ES, no ano de 2008, observou-se que esta abrangia quase a metade do total de áreas verdes locais (Tabela 2). Entretanto, houve uma redução das áreas arborizadas no ano de 2013 (Figura 3), apesar de ter ocorrido em menor escala em comparação com a classe de faixas de verde que são representadas por locais com cobertura de gramíneas e forrações. 


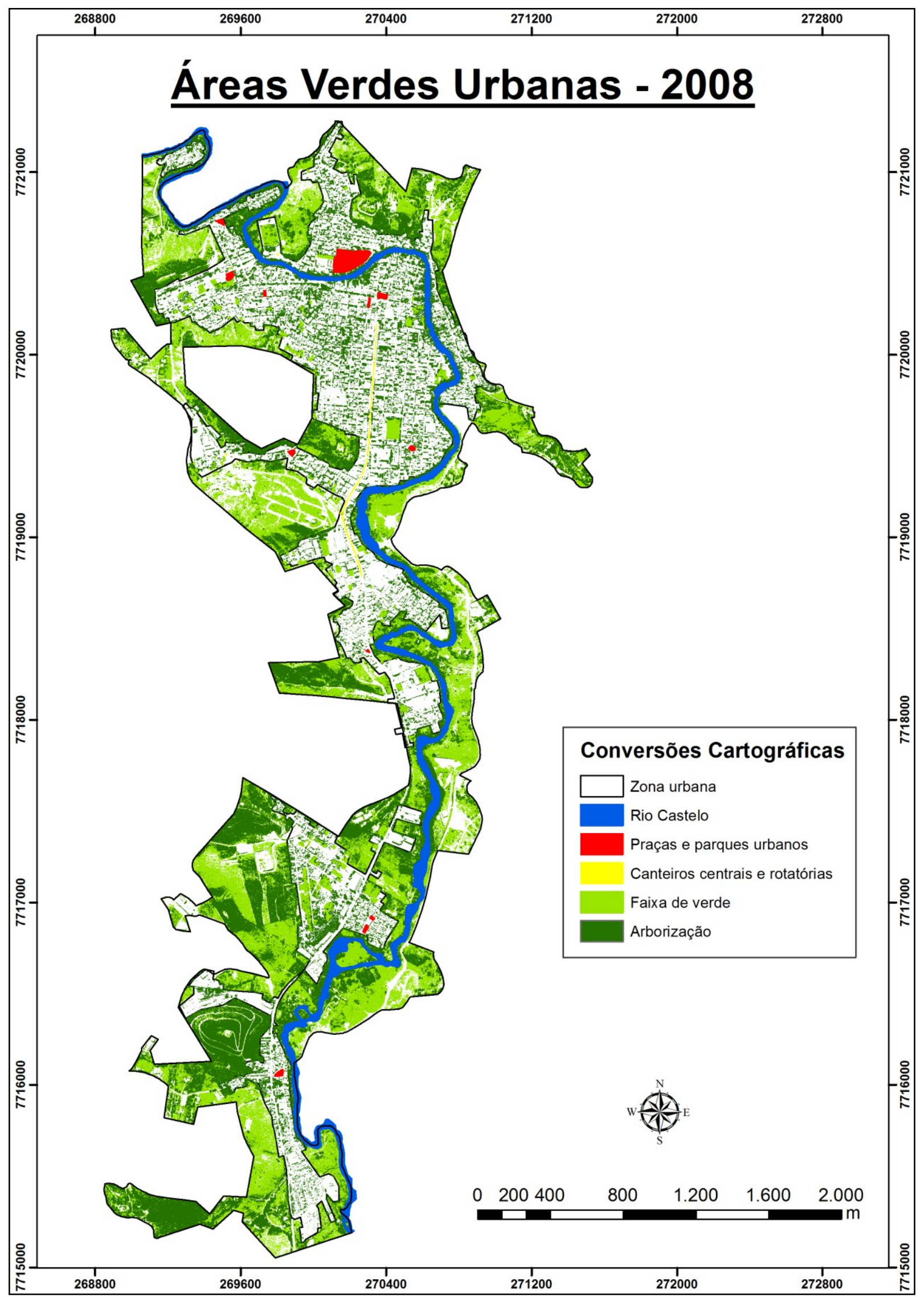

Figura 2. Distribuição das áreas verdes urbanas na cidade de Castelo no ano de 2008.

Figure 2. Distribution of the urban green areas in the city of Castelo for the year 2008. 
Tabela 2. Representatividade das classes de áreas verdes no mapeamento do ano de 2008.

Table 2. Representativeness of the classes of green areas in the mapping of the year of 2008.

\begin{tabular}{ccc}
\hline Classes & Área $\mathbf{( m}^{\mathbf{2}} \mathbf{)}$ & Porcentagem \\
\hline Arborização & 1.909 .297 & $49,86 \%$ \\
Faixas de verde & 1.886 .160 & $49,26 \%$ \\
Canteiros centrais e rotatórias & 5.144 & $0,13 \%$ \\
Praças e parques & 28.499 & $0,74 \%$ \\
Total de Áreas Verdes & 3.829 .100 & $100 \%$ \\
Área da zona urbana & 6.320 .172 & - \\
Porcentagem de área verde em relação à área urbana (PAV) & - & $60,59 \%$ \\
\hline
\end{tabular}

A criação e manutenção das áreas verdes urbanas constituem uma das vertentes do chamado ordenamento urbano e territorial, em que as mesmas desempenham várias funções, destacando-se os aspectos ecológicos, de saúde, estéticos e de lazer. A criação de áreas verdes reduz os problemas ambientais resultantes da ocupação antrópica desordenada nas cidades (CAMPOS; CASTRO, 2017).

Araújo e Ferreira (2014) alertam que, quando não há nas cidades uma preocupação com planejamento e execução da ampliação das áreas arborizadas, ocorre uma deterioração paulatina da qualidade de vida e da biodiversidade, com efeitos sobre processos ecológicos, como é o caso da falta de habitats que podem sustentar uma fauna associada. Já Loboda e De Angelis (2005) enfatizam que as áreas verdes funcionam também como um filtro de materiais particulados no ar e atenuam o calor do sol, contribuindo na melhoria da qualidade atmosférica em geral. Assim, já é conhecido que perdas na arborização, em concomitância com o crescimento populacional e o aumento do número de veículos automotores, afetam negativamente os indicadores de qualidade ambiental em várias cidades, o que não seria diferente para a área urbana de Castelo-ES.

As áreas de faixas de verde (campos e gramíneas) encontradas em 2008 foram significativas, apesar de ter ocorrido uma redução expressiva no período considerado (visto no mapeamento o ano de 2013), conforme representado na Tabela 3. Porém, o percentual delas é inferior à de outras cidades, como Cachoeiro de Itapemirim-ES, onde totaliza $68,96 \%$ das áreas verdes (PIROVANI et al., 2012). A presença dessa classe também é um fator positivo, tendo em vista considerar os locais onde há possibilidade de haver maior permeabilidade da água de chuva para abastecimento dos lençóis freáticos locais, contribuindo com a redução de pontos de alagamentos nos períodos de precipitação elevada e com a regulação do fluxo hídrico natural do rio Castelo, que passa na área urbana do município. Por outro lado, a redução observada dessa classe é um fator preocupante, pois influi no aumento de áreas impermeáveis, um padrão que pode ser resultado das reduções de espaços verdes dedicados aos projetos de paisagismo em residências cada dia mais verticalizadas. 


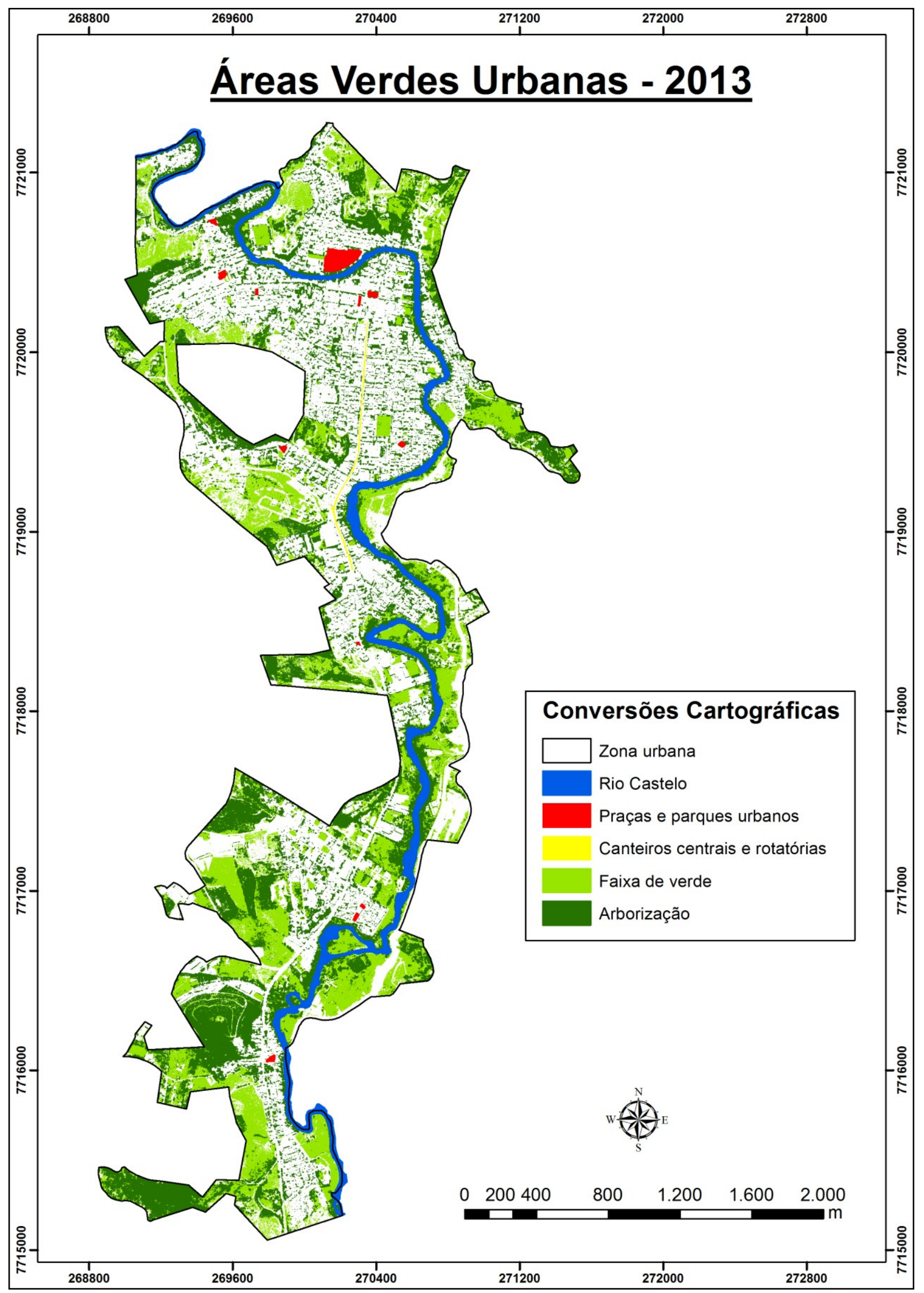

Figura 3. Distribuição das áreas verdes urbanas na cidade de Castelo referente no ano de 2013. Figure 3. Distribution of the urban green areas in the city of Castelo for the year 2013. 
A área verde total na zona urbana ocupa $3,82 \mathrm{Km}^{2}$, número superior à de outras cidades, como Goiânia-GO (2,87 Km²) segundo Silva et al. (2009). Já as praças e parques representaram apenas $0,74 \%$ das áreas verdes mapeadas, número inferior aos 3,82\% estimados por Pirovani et al. (2012) em Cachoeiro de Itapemirim-ES. Além disso, o valor de $28.499 \mathrm{~m}^{2}$ é inferior ao encontrado em cidades, como Itaú de Minas-MG (120.993 $\mathrm{m}^{2}$ ), conforme Santos e Magri (2018). Segundo os mesmos autores, Itaú de Minas-MG dispõe de uma área urbana igual a 3.958.475 $\mathrm{m}^{2}$, ou seja, nesta área urbana há maiores espaços ocupados por praças e parques urbanos em comparação com o município de Castelo-ES, que possui maior área urbana. Isso constitui um problema para a zona urbana da cidade, caso haja um forte processo de expansão urbana. As praças públicas, de acordo com Benini e Martin (2010), possuem como uma das funções embelezar a cidade, dispondo-se como um espaço convidativo ao lazer e as mais variadas atividades para atender as necessidades humanas. A Tabela 3 demonstra os dados quantitativos para cada classe de áreas verdes referentes ao mapeamento do ano de 2013.

Tabela 3. Representatividade das classes de áreas verdes no mapeamento do ano de 2013.

Table 3. Representativeness of the classes of green areas in the mapping of the year of 2013.

\begin{tabular}{ccc}
\hline Classes & Área $\left.\mathbf{( m}^{\mathbf{2}}\right)$ & Porcentagem \\
\hline Arborização & 1.725 .514 & $53,69 \%$ \\
Faixas de verde & 1.454 .597 & $45,26 \%$ \\
Canteiros centrais e rotatórias & 5.144 & $0,16 \%$ \\
Praças e parques & 28.499 & $0,89 \%$ \\
Total de Áreas Verdes & 3.213 .755 & $100 \%$ \\
Área da zona urbana & 6.320 .172 & - \\
Porcentagem de área verde em relação a área urbana (PAV) & - & $50,85 \%$ \\
\hline
\end{tabular}

Em consonância, os locais com ornamentação pelo paisagismo das praças e parques, canteiros centrais e rotatórias ocupam uma área relativamente pequena. Embora não tenham grande influência sobre as condições térmicas locais, tais classes exercem um papel fundamental na melhoria da qualidade de vida da população, por possibilitarem convívio social em meio a ambiente com harmonização paisagística e contato direto com a natureza.

Houve uma redução em aproximadamente $10 \%$ do valor da PAV estimada nos mapeamentos entre os anos analisados, o que é preocupante quanto à qualidade do meio ambiente urbano de Castelo-ES, já que esta medida deveria estar aumentando ao longo dos anos pelo plantio de novas árvores. Apesar desse agravante, os percentuais de áreas verdes urbanas observados para Castelo-ES são superiores aos de outras cidades, como AmericanaSP (6,73\%), segundo Ávila e Pancher (2015) e Itaú de Minas-MG (27,64\%), conforme Santos e Magri (2018). Pina e Santos (2012) destacam que muitos gestores públicos têm visto a vegetação como um elemento destinado apenas à valorização estética, possuindo uma visão limitada, que 
também é prevalecente em muitos proprietários de imóveis que afetam a arborização urbana por meio de cortes e podas feitas sem autorização e/ou orientação técnica. Essa justificativa pode ser atribuída à redução da arborização no período analisado, que foi de $183.783 \mathrm{~m}^{2}$ (cerca de 9,63\% em relação à área de arborização em 2008.

Souza, Scopel e Martins (2014), em estudos sobre as áreas verdes urbanas de JataíGO, constataram que, em um intervalo de aproximadamente seis anos, houve uma redução de $46,77 \%$ das áreas verdes. Número muito superior à redução observada para a zona urbana de Castelo-ES. Essas reduções nas cidades podem ser majoritariamente atribuídas aos processos de urbanização que, segundo Araújo e Aguirre (2013), propiciam um notável distanciamento entre cidade e natureza. Tais processos estão geralmente associados ao surgimento de espaços com formas cada vez mais artificiais.

$\mathrm{Na}$ Figura 4, um gráfico ilustrando os acréscimos e decréscimos na porcentagem da arborização por bairro da zona urbana de Castelo-ES entre os anos de 2008 a 2013 é apresentado. O menor percentual de área arborizada registrado foi no bairro Cava Roxa, com $19 \%$, ao passo que o maior valor observado foi na localidade de Volta Redonda, com $42 \%$. Essa grande variabilidade na porcentagem de área arborizada por bairros coincide também com resultados dos estudos feitos por Toledo, Batista e Maia (2011). Os mesmos autores observaram que o percentual de arborização variou de $7 \%$ a $37 \%$ em bairros de Taubaté-SP, uma dissimilaridade entre bairros também vista no município de Castelo-ES. No entanto, a faixa de arborização aqui analisada pode ser considerada satisfatória, quando comparada aos valores de cidades como Taubaté-SP (TOLEDO; BATISTA; MAIA, 2011).

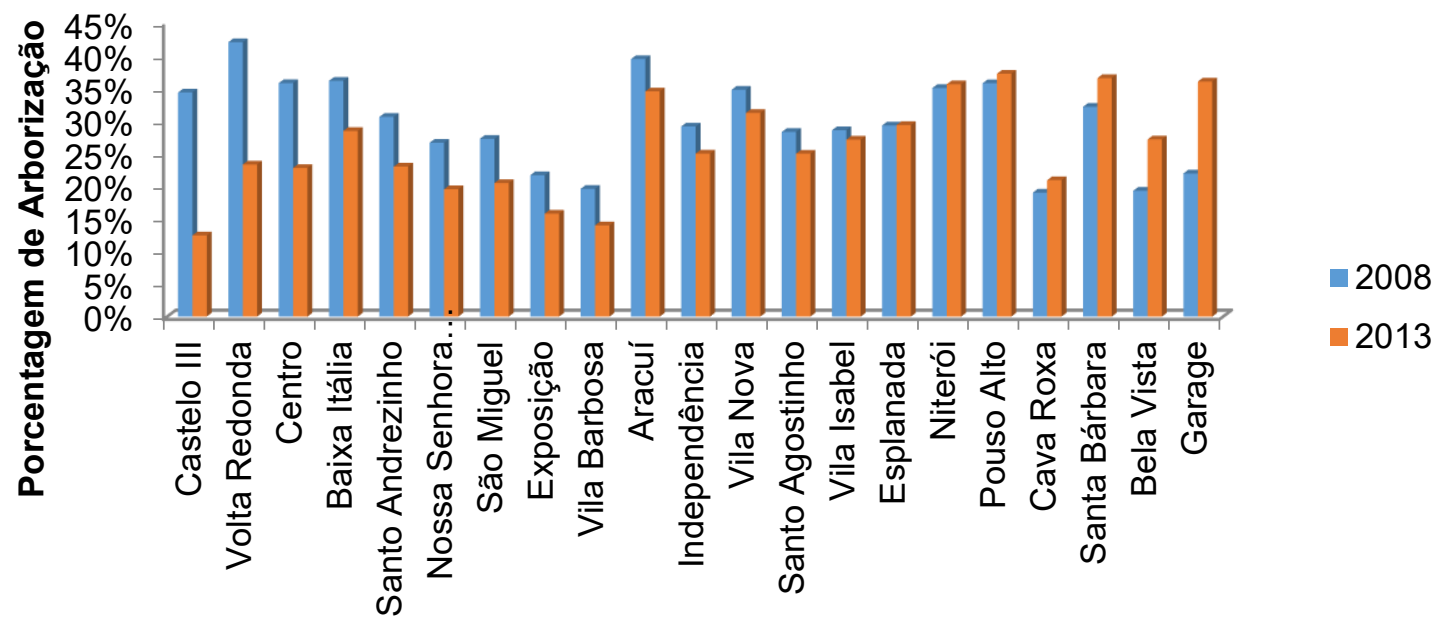

Figura 4. Incrementos e decrementos da área arborizada por bairros de Castelo-ES entre 2008 e 2013. Figure 4. Increases and decreases of the afforested area by neighborhoods of Castelo-ES between 2008 and 2013. 
Contudo, é importante ressaltar que alguns bairros não possuem praças ou parques urbanos, como é o caso dos bairros Vila Barbosa e Bela Vista. Portanto, a área arborizada nessas localidades é constituída apenas pela arborização de calçada, quintais e, em certos bairros, pela mata ciliar do rio Castelo. Diante desse cenário, Araújo e Aguirre (2013) afirmam que o processo de modificações no planejamento urbanístico de uma localidade que suprime áreas de praças resulta na diminuição da qualidade ambiental e, consequentemente, na qualidade de vida da população.

Com relação à espacialização da dinâmica espaço-temporal da arborização, no período de cinco anos, dos 21 bairros listados, é visível que 14 apresentaram queda nas áreas arborizadas (Figura 4 e 5). Os maiores decréscimos percentuais visualizados foram nos bairros Castelo III e Volta Redonda, que tiveram perda aproximada em $20 \%$ da arborização. Apenas cinco bairros tiveram aumento na área arborizada, sendo que os maiores valores foram vistos para os bairros Garage e Bela Vista, entre $8 \%$ a $14 \%$.

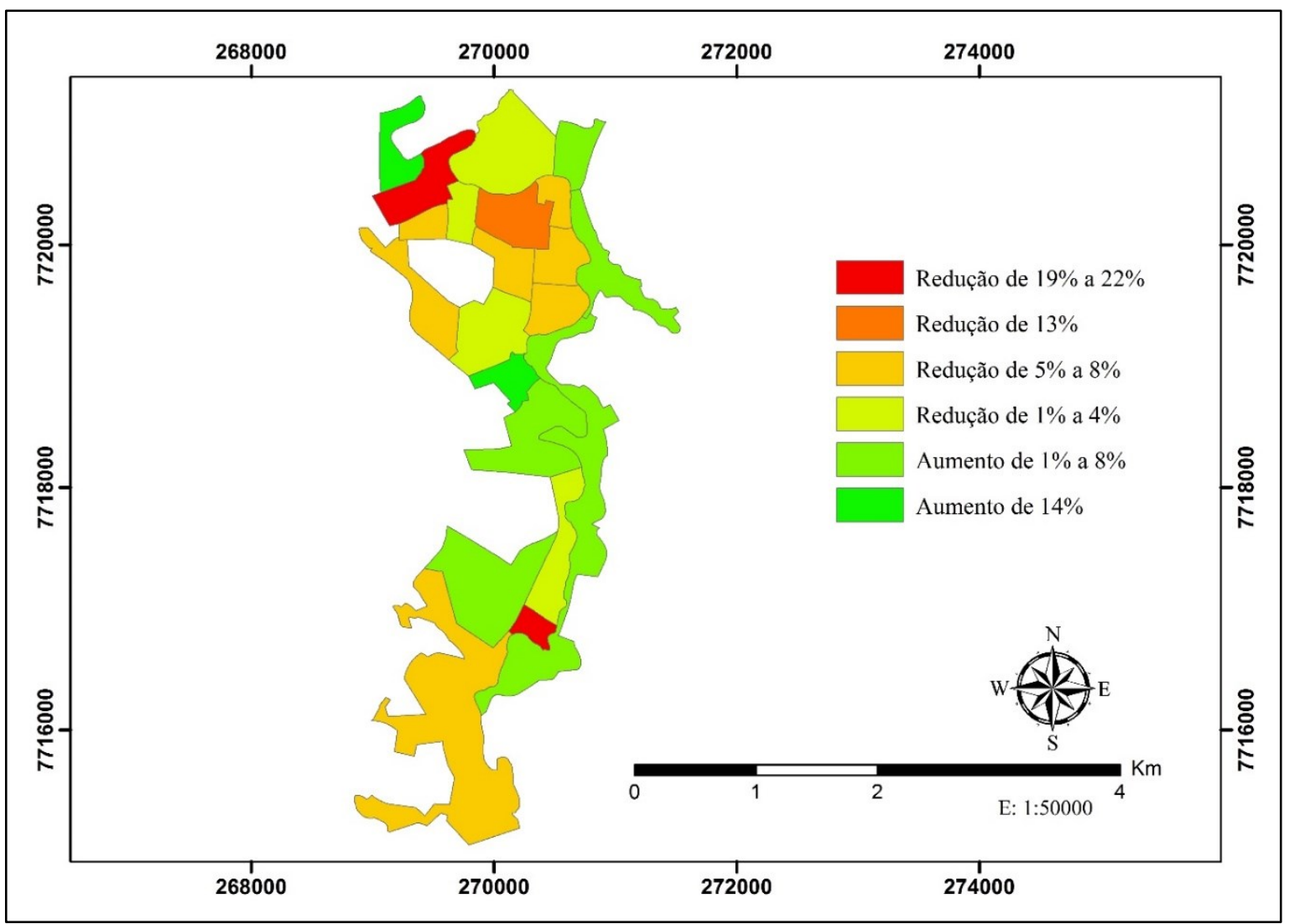

Figura 5. Dinâmica espaço-temporal da área arborizada por bairros de Castelo-ES entre 2008 a 2013.

Figure 5. Spatial-temporal dynamics of the afforested area of Castelo-ES neighborhoods between 2008 and 2013

A evolução na arborização ao longo desse período mostra uma situação preocupante para $66 \%$ dos bairros da zona urbana do município estudado. Esse fato se torna mais iminente 
quando são analisados os números de forma mais generalizada. No mapeamento do ano de 2008 o percentual de arborização chegou a ser bem próximo ou superior a 40\% em determinados bairros, fato que não ocorreu no mapeamento de 2013. Essa situação corrobora ao resultado observado por Toledo, Batista e Maia (2011), em que o percentual de áreas verdes por bairro não ultrapassou $40 \%$ no município de Taubaté-SP.

Em ambos os mapeamentos, as áreas verdes estão concentradas em apenas alguns pontos (onde não houve um processo de urbanização muito impactante sobre essa cobertura vegetal). Também é perceptível a queda nas áreas de faixa de verde em algumas partes da zona urbana, fato atribuído à instalação de edifícios e os demais empreendimentos localizados nas periferias da cidade, o que ilustra o processo de crescimento da malha urbana.

A análise de Santos, Rufino e Barros Filho (2017) demonstra que a impermeabilização do solo contribui diretamente com o aumento do escoamento superficial. Isso se dá devido ao aumento da sobrecarga do sistema de micro drenagem urbano, em função da expansão da ocupação e também da verticalização, já que os edifícios multifamiliares aproveitam mais completamente os terrenos que são menores e, ainda, reduzindo paulatinamente o espaço disponível para implantar áreas verdes. Isso é um fator preocupante para a cidade de Castelo/ES, pois pode somar para o agravamento de problemas como as enchentes e os alagamentos, especialmente em bairros onde houve diminuição drástica da vegetação como demonstrado por meio das figuras 4 e 5 .

Outro fator preocupante é a pouca vegetação ciliar presente no entorno do rio Castelo. Em ambas as análises anuais, extensas áreas ocupadas com essa cobertura do solo não foram percebidas, tampouco um avanço da cobertura vegetal nos espaços ciliares vegetados. Na cidade de Castelo-ES, a adoção de melhorias quanto à cobertura da vegetação ciliar do rio Castelo favoreceria muitos bairros que não possuem praças ou parques urbanos com vegetação e que tem seus territórios atravessados pelo curso hídrico local.

A Tabela 4 mostra os valores estimados do Índice de Áreas Verdes (IAVT) e o Índice de Áreas Verdes Recreativas (IAVR) para os anos de 2008 e 2013. De acordo com o censo demográfico do IBGE de 2010, a população residente na zona urbana no município de CasteloES era de 21.817 habitantes. Os resultados, em ambos os mapeamentos, referentes à ocupação de cada classe das áreas verdes na paisagem urbana demonstram um elevado Índice de Áreas Verdes (IAVT), acima do mínimo de $12 \mathrm{~m}^{2} /$ habitante, sugerido pela Organização Mundial da Saúde (OMS), e do mínimo de $15 \mathrm{~m}^{2} /$ habitante, sugerido pela Sociedade Brasileira de Arborização Urbana (SBAU).

Além disso, os valores obtidos para o IAVT são superiores aos de outras cidades brasileiras, como o de Cachoeiro de Itapemirim-ES (35,04 $\mathrm{m}^{2} /$ habitante, segundo Pirovani et al. (2012)); Paulínia-SP (96,32 m²/habitante), conforme Bargos e Matias (2012) e Itaú de Minas-MG 
(68,057 $\mathrm{m}^{2}$ /habitante), segundo Santos e Magri (2018). Apesar disso, houve uma redução do IAVT no período considerado, o que pode ser considerado um alento diante da evolução do processo de urbanização local.

Tabela 4.Valores do IAVT e IAVR para os mapeamentos dos anos 2008 e 2013.

Table 4.IAVT and IAVR values for the 2008 and 2013 mappings.

\begin{tabular}{ccc}
\hline Itens & $\mathbf{2 0 0 8}$ & $\mathbf{2 0 1 3}$ \\
\hline Índice de Áreas Verdes (IAVT) & $175,51 \mathrm{~m}^{2} /$ habitante & $147,31 \mathrm{~m}^{2} /$ habitante \\
Índice de Áreas Verdes Recreativas (IAVR) & $1,31 \mathrm{~m}^{2} /$ habitante & $1,31 \mathrm{~m}^{2} /$ habitante \\
\hline
\end{tabular}

$\mathrm{O}$ valor do IAVR estimado é relativamente muito baixo perante o elevado IAVT do município, sendo inferior ao de cidades como Itaú de Minas-MG (8,2 $\mathrm{m}^{2} /$ habitante), como demonstram Santos e Magri (2018). Diante do valor de IAVR estimado, Santos e Magri (2018) propõem que deva haver investimentos em novos espaços recreativos e que estes, apesar de terem custo inicialmente considerado elevado, congregam benefícios inestimáveis que estão relacionados à saúde e ao bem-estar da população. Tais benefícios compensariam os gastos de dinheiro público com tais tipos de investimentos.

\section{CONCLUSÕES}

De maneira geral, o município de Castelo-ES é bem arborizado, apresentando Índice de Áreas Verdes (IAVT) elevado, e satisfazendo o mínimo recomendado pela Organização Mundial da Saúde e Sociedade Brasileira de Arborização Urbana. No entanto, a redução considerável do IAVT e, consequentemente, das áreas de arborização e das faixas de verde da maioria dos bairros, constitui um alerta para a qualidade ambiental na cidade e para o planejamento urbano. Além disso, a distribuição das áreas arborizadas ocorre, em maior escala, na arborização de calçadas e em áreas ainda não efetivamente construídas, e o Índice de Áreas Verdes Recreativas (IAVR) foi muito aquém do ideal para uma cidade em crescimento.

Mediante aos problemas que podem decorrer dos decrementos observados nas áreas verdes, é de suma importância que o setor público municipal realize trabalhos que possam incentivar o incremento das áreas arborizadas em vias públicas e calçadas, bem como o estabelecimento de novas áreas recreativas em parques e praças públicas, sobretudo em bairros que ainda não as possuam. Finalmente, trabalhos de revitalização nas áreas recreativas já existentes e na mata ciliar, no entorno do rio Castelo, também serão necessários, e que ambas estas medidas estejam associadas ao Plano de Arborização, visando ampliar a qualidade de vida da população e do ambiente pelos benefícios que um aumento nas áreas verdes poderá propiciar. 


\section{AGRADECIMENTOS}

Agradecemos ao Centro Universitário São Camilo (ES) pela disponibilização da estrutura de laboratórios e apoio para produção científica. À Fundação de Amparo à Pesquisa e Inovação do Estado do Espírito Santo (FAPES) pela concessão de auxílio financeiro, por meio do Edital No 22/2018 CNPQ/FAPES - Programa Primeiros Projetos - PPP (T.O. 009/2019 / Processo 85320285), e ao Instituto Estadual de Meio Ambiente e Recursos Hídricos (IEMA) e Instituto Jones dos Santos Neves (ISJN) pela disponibilização do ortofotomosaico e do banco de dados georreferenciados.

\section{REFERÊNCIAS}

ALBERTO, R. S. Funcionalidade e usos de áreas verdes urbanas sob o olhar da educação ambiental. Revista Brasileira de Educação Ambiental, São Paulo, v. 12, n. 3, p. 296-317, 2017.

ÁVILA, M. R; PANCHER, A. M. Estudo das áreas verdes urbanas como indicador de qualidade ambiental no município de Americana-SP. Revista Brasileira de Cartografia, Uberlândia, v. 3, n. 67, p. $527-544,2015$.

ARAÚJO, C. M. A; FERREIRA, C. C. M. Áreas verdes públicas em Juiz de Fora, MG: uma análise do estado da arte atual. Revista GeoUERJ, Rio de Janeiro, v. 2, n. 25, p. 250-275, 2014.

ARAÚJO, R. S.; AGUIRRE, C. A. F. Espaços públicos: áreas verdes em Campos dos Goytacazes e São João da Barra - RJ. Revista Perspectivas Online, Campos dos Goytacazes, v. 8, n.3, p. 56-77, 2013.

BARGOS, D. C; MATIAS, L. F. Mapeamento e análise de áreas verdes urbanas em Paulínia (SP): estudo com aplicação de geotecnologias. Sociedade \& Natureza, Uberlândia, v. 0, n. 1, p. 143-156, 2012.

BENINI, S. M; MARTIN, E. S. Decifrando as áreas verdes públicas. Revista Formação, Presidente Prudente, v. 2, n. 17, p. 63-80, 2010.

CAMPOS, R. B. F.; CASTRO, J. M. Áreas verdes: espaços urbanos negligenciando a saúde. Revista Saúde \& Transformação Social, Florianópolis, v. 8, n. 1, p. 106-116, 2017.

DORIGO, T. A.; LAMANO-FERREIRA, A. P. N. Contribuições da percepção ambiental de frequentadores sobre praças e parques no Brasil (2009-2013): revisão bibliográfica. Revista de Gestão Ambiental e Sustentabilidade, São Paulo, v. 4, n. 3, p. 31-45, 2015.

FIORESE, C. H. U.; SILVA-FILHO, G. Áreas verdes urbanas do município de Guaçuí-ES, Brasil. Enciclopédia Biosfera, Goiânia, v. 16, n. 29, p. 816-826, 2019.

FURLANETO, T. A, SILVA, W. C. M.; CORREA, M. Avaliação de áreas verdes urbanas no município de Balneário Camboriú-SC. Cadernos Acadêmicos, Tubarão, v.6, n.1, p.35-55, 2014.

INSTITUTO CAPIXABA DE PESQUISA, ASSISTÊNCIA TÉCNICA E EXTENSÃO RURAL (INCAPER). Programa de assistência e extensão rural PROATER 2011-2013: Castelo. Disponível em: <https://incaper.es.gov.br/media/incaper/proater/municipios/Caparao/Castelo. pdf>. Acesso em: 20 abr. 2019. 
INSTITUTO BRASILEIRO DE GEOGRAFIA E ESTATÍSTICA (IBGE). Sinopse do censo demográfico 2010: Espírito Santo. Disponível em:<https://censo2010.ibge.gov.br/sinopse/inde x.php?dados=29\&uf=32> Acesso em: 6 jan. 2019.

LOBODA, C. R.; DE ANGELIS, B. L. D. Áreas verdes públicas urbanas: conceitos, usos e funções. Revista Ambiência, Guarapuava, v. 1, n.1, p. 125-139, 2005.

MACIEL, T. T.; BARBOSA, B. C. Áreas verdes urbanas: história, conceitos e importância ecológica. CES Revista, Juiz de Fora, v. 29, n. 1, p. 30-42, 2015.

NASCIMENTO, I. S. do.; CRUZ, C. B. M.; NEVES, S. M. A. da S.; GALVANIN, E. A. dos S. Avaliação da exatidão dos classificadores Maxver e Isso Cluster do software ArcGIS for desktop, com uso de imagem Landsat 8 do município de Cáceres/MT. Revista Continentes, v. 5, n. 8, p. 48-62, 2016.

PANCHER, A. M.; ÁVILA, M. R. O uso de geotecnologias na determinação do percentual de áreas verdes urbanas no município de Americana-SP. Revista Geonorte, Manaus, v. 2, n. 4, p. 1662-1673, 2012.

PINA, J. H. A.; SANTOS, D. G. A influência das áreas verdes urbanas na qualidade de vida: o caso dos Parques do Sabiá e Victório Siquierolli em Uberlândia-MG. Revista Ateliê Geográfico, Goiânia, v. 6, n. 1, p. 143-169, 2012.

PIROVANI, D. B.; SILVA, A. G.; OLIVEIRA, O. M.; CALIMAN, J. P. Áreas verdes urbanas de Cachoeiro de Itapemirim. Revista Enciclopédia Biosfera, Goiânia, v. 8, n. 15, p. 171-179, 2012.

SANTOS, K. A.; RUFINO, I. A. A.; BARROS FILHO, M. N. M. Impactos da ocupação urbana na permeabilidade do solo: o caso de uma área de urbanização consolidada em Campina GrandePB. Engenharia Sanitária e Ambiental, v. 22, n. 5, p. 943-952, 2017.

SANTOS, C. D. M.; MAGRI, R. A. F. Áreas verdes urbanas do município de Itaú de Minas-MG, Brasil. Revista Enciclopédia Biosfera, Goiânia, v. 15, n. 27, p. 42-53, 2018.

SANTOS, P. A. B.; NETTO, J. A. V.; CASTRO, C. M.S. Geoprocessamento aplicado a análise de áreas verdes nas imediações da Lagoa da Paixão, Valéria - Salvador/BA. In: IV SIMPÓSIO BRASILEIRO DE CIÊNCIAS GEODÉSICAS E TECNOLOGIAS DA GEOINFORMAÇÃO, 4., 2012, Recife. Anais.... Recife: UFPE, 2012.

SILVA, G. N. F.; NETO, H. M. P.; DINIZ, D. C. C.; ROCHA, G. F. O uso do programa Spring no cálculo do Índice de Área Verde em Goiânia. In: SIMPÓSIO BRASILEIRO DE SENSORIAMENTO REMOTO, 14., 2009, Natal. Anais... São José dos Campos: INPE, 2009, p. 867-873.

SILVA, C. S. S. S, PEREIRA, A. B.; WICKERT, M. Estado da arte de valoração ambiental de áreas verdes urbanas no Rio Grande do Sul. In: SEMINÁRIO CIDADE BEM TRATADA, 7., 2018, Porto Alegre. Anais... São Leopoldo: UNISINOS, 2018, p. 1-11.

SOUZA, M. R.; SCOPEL, I.; MARTINS, A. P. Áreas verdes no sítio urbano de Jataí (GO). Revista Caminhos de Geografia, Uberlândia, v. 15, n. 51, p. 181-198, 2014.

TOLEDO, M. C. B.; BATISTA, G.; MAIA, J. S. Avaliação das áreas verdes urbanas e da diversidade de aves do Município de Taubaté, SP. In: SIMPÓSIO BRASILEIRO DE SENSORIAMENTO REMOTO, 15., 2011, Curitiba. Anais... São José dos Campos: INPE, 2011, p. 3174-3181. 